ELECTRONIC LETTER

\title{
NPHP1 gene deletion is a rare cause of Joubert syndrome related disorders
}

\author{
M Castori, E M Valente, M A Donati, S Salvi, E Fazzi, E Procopio, T Galluccio, F Emma, \\ B Dallapiccola, E Bertini, the Italian MTS Study Group*
}

J Med Genet 2005;42:e9 (http://www.jmedgenet.com/cgi/content/full/42/2/e9). doi: 10.1136/jmg.2004.027375

$\mathrm{J}$

oubert syndrome (JS) is an autosomal recessive disorder presenting with congenital hypotonia evolving into ataxia, developmental delay, and either oculomotor apraxia or abnormalities of respiratory pattern or both. JS is characterised, using magnetic resonance imaging (MRI), by cerebellar vermian hypoplasia and a complex brain stem malformation called the "molar tooth sign" (MTS), consisting of thickened, elongated, and reoriented superior cerebellar peduncles and a deep interpeduncular fossa. ${ }^{1}$ JS has been classified into two groups, $\mathrm{A}$ and $\mathrm{B}$, the latter being characterised by the occurrence of retinal and/or renal involvement. $^{2}$

Key associated features of JS are retinal dystrophy and nephronophthisis, but other manifestations include ocular colobomas, liver fibrosis, and polydactyly. The variable involvement of other organs identifies a large spectrum of syndromes sharing the MTS (such as Arima, COACH, and Senior-Löken syndromes) which, together with JS, are termed Joubert syndrome related disorders (JSRD) or MTS related syndromes. ${ }^{3-5}$

To date, three genetic loci associated with JSRD have been mapped to chromosome 9q34.3 (JBTS1), 11pl1.2-q12.3 (JBTS2), and 6q23 (JBTS3). ${ }^{6-9}$ Recently, mutations in the AHIl gene have been identified in three JBTS3 linked families presenting with a pure cerebellar phenotype. ${ }^{10}$

Isolated nephronophthisis (NPH) is an autosomal recessive tubulointerstitial medullary kidney disease and is one of the most frequent monogenic causes of chronic renal failure in childhood. Four genes causing infantile or juvenile NPH have been cloned so far (NPHPl to 4) ${ }^{11-14}$ Of these, NPHPl is the most commonly mutated gene, being responsible for at least $50 \%$ of cases with juvenile NPH. ${ }^{15}{ }^{16}$ A large homozygous deletion of the NPHPl gene is found in more than $80 \%$ of patients, while less than $5 \%$ are compound heterozygote for the gene deletion and a point mutation on the other allele. ${ }^{16}$ Most patients with the NPHPl deletion demonstrate progressive normotensive renal failure in the second decade of life, associated with severe polyuria and anaemia. Some patients, however, present more complex phenotypes resembling JSRD, such as NPH associated with pigmentary retinopathy (Senior-Löken syndrome), ${ }^{17}$ congenital oculomotor apraxia (COGAN syndrome), ${ }^{18}{ }^{19}$ or cerebellar vermis hypoplasia. ${ }^{20} 21$

Recently, Parisi and colleagues screened 25 patients with JS type B for the NPHPl deletion, which was found in two siblings with a cerebello-renal phenotype and in an additional sporadic case with NPH and mild psychomotor delay but no cerebellar signs. None of the three patients had retinal involvement. MRIs from all patients showed an MTS characterised by moderate inferior vermis hypoplasia with elongated but not thickened superior cerebellar peduncles. ${ }^{22}$

Herein we describe the results of a screening for NPHPI deletion in a group of Italian patients with various MTS associated phenotypes.

\section{Key points}

- Joubert syndrome (JS) is a neurological disorder characterised by a complex cerebellar and brainstem malformation, the so called "molar tooth sign" (MTS). JS can be associated with several abnormalities in other organs, identifying a large spectrum of "Joubert syndrome related disorders" (JSRD). Isolated nephronophthisis (NPH) is an autosomal recessive tubulointerstitial medullary cystic kidney disease, which can be found in some JSRD. Among the four genes responsible for isolated NPH (NPHP1-4), NPHP1 deletions have been found in two families with JS plus NPH.

- We tested 40 JSRD probands with proven MTS for NPHP1 deletions. Homozygous deletions were tested by performing two multiplex PCR with two microsatellite markers (one control marker and one internal deletion marker) resolved on agarose gel. Five markers within the common NPHPI deletion region were genotyped to test heterozygous deletions.

- A single NPHP1 homozygous deletion was found in a patient presenting with cerebellar, retinal, and kidney involvement, while heterozygous deletions were excluded in the others. The appearance of MTS in the patient with NPHP1 deletion was characteristic with moderate cerebellar vermis hypoplasia and elongated but not thickened superior cerebellar peduncles.

- We confirm that NPHP1 deletions can be a rare cause of JSRD and broaden the NPHP1 associated clinical spectrum. In all NPHP1 JSRD patients so far reported, the MTS shows remarkably similar features, which might be specifically associated with NPHP1 deletions.

\section{METHODS}

We searched for NPHPI deletions in 40 probands with JSRD and proven MTS, ascertained through several clinicians participating in the Italian MTS Study Group. As NPH can be asymptomatic for years before manifesting renal insufficiency, we included in the study all patients with a confirmed MTS, independently of the presence of renal involvement. A blood sample was drawn from patients after obtaining written parental informed consent for NPHPl diagnostic testing.

Abbreviations: JS, Joubert syndrome; JSRD, Joubert syndrome related disorders; MRI, magnetic resonance imaging; MTS, molar tooth sign; $\mathrm{NPH}$, nephronophthisis 


\begin{tabular}{|llc|}
\hline \multicolumn{2}{|l|}{ Table 1 Patient clinical data } & \\
\hline Characteristics & Patients $(\mathbf{n}=\mathbf{4 0})$ & $\%$ \\
\hline Sex (M/F) & $18 / 22$ & $45 / 55$ \\
Neurological features & 40 & 100 \\
Hypotonia/ataxia & 35 & 87 \\
Mental retardation & 30 & 75 \\
Oculomotor apraxia & 34 & 85 \\
Breathing abnormalities & 17 & 42 \\
Ocular features & 21 & 52 \\
Retinal dystrophy* & 18 & 45 \\
Ocular colobomas & 3 & 7 \\
Renal features & 15 & 37 \\
NPH/urinary concentration defects & 10 & 25 \\
Cystic kidney disease & 3 & 7 \\
Other renal disease & 2 & 5 \\
Combined ocular and renal disease & 11 & 27 \\
Hepatic disease & 3 & 7 \\
Polydactyly & 8 & 20 \\
\hline *Including pigmentary retinopathy and Leber congenital amaurosis. \\
\hline
\end{tabular}

Genomic DNA was isolated by standard methods. Molecular analysis of the NPHPl gene was performed using a two step approach. First, an established diagnostic algorithm ${ }^{16}$ with minor modifications was used to identify homozygous gene deletions. Two previously described markers (804/6 and 9657T-1/2) ${ }^{16}$ localised within the common NPHPI deletion interval were amplified in two multiplex PCR (A and B) with control markers D9S1826 and D11S1978, mapping outside the deleted region. PCR products were loaded on a $3 \%$ agarose gel along a 100 bp DNA size standard and electrophoresed at $100 \mathrm{~V}$ for $2 \mathrm{~h}$.

As a second step, we sought to identify possible heterozygous deletions of the NPHPl gene. Five highly informative microsatellite markers located within the deleted region (cen - del-16 - del-2 - del-10 - del-5-5(2) - del-9 - tel) were genotyped in the probands. These markers have been specifically designed and optimised by Heninger and colleagues for this purpose. ${ }^{23}$ Indeed, the identification of at least one heterozygous marker would exclude the presence of a heterozygous NPHPl deletion.

\section{RESULTS}

Clinical characteristics of the 40 patients are summarised in table 1 .

Fifteen patients had pure JS (type A), while the remaining 25 presented with renal or retinal involvement or both. A homozygous deletion of the NPHPl gene was found only in one of 40 probands (EC, fig 1). Genotyping of the five informative microsatellite markers excluded heterozygous deletions in 36 probands who carried at least one heterozygous marker, while for three patients the DNA sample was insufficient to complete the analysis. None of the five markers could be amplified in patient EC carrying the homozygous NPHPl deletion.

This patient is a 3 year old female born at term after a normal pregnancy to apparently non-consanguineous Italian parents. Family history was unremarkable. She is the second of three children, with two healthy sibs. No breathing abnormalities were reported during the perinatal period. Physical examination at birth failed to show gross dysmorphisms. The child was able to sit unassisted at the age of 12 months, to pronounce simple words at 16 months, and to walk at 20 months. The neurological evaluation at 3 years of age revealed hypotonia, mild psychomotor delay, oculomotor apraxia, and ataxic gait. A brain MRI documented an MTS with cerebellar vermis hypoplasia, narrowing of the isthmus and elongation of the superior cerebellar peduncles (fig 2).

During the first year of life the patient developed mild polyuria. Urine analysis revealed low specific gravity (1006) in the absence of sediment abnormalities or proteinuria. Renal ultrasonography and serum creatinine levels $(0.4 \mathrm{mg} /$ dl) were normal. Maximal urine osmolarity after water restriction was low $\left(579 \mathrm{mOsm} / \mathrm{kg} / \mathrm{H}_{2} \mathrm{O}_{2}\right.$; normal values $>800 \mathrm{mOsm} / \mathrm{kg} / \mathrm{H}_{2} \mathrm{O}_{2}$ ), indicating a reduced urinary concentrating ability. Renal biopsy was not performed.

The ophthalmologic assessment revealed severe visual impairment and retinal pigmentary changes. The electroretinogram was significantly delayed and attenuated mainly in its photopic component with present flash visual evoked potentials. Liver function tests, a liver ultrasound scan, and a standard karyotype ( 550 band resolution) were normal.

\section{DISCUSSION}

The genetic basis of JSRD is still poorly understood, however, significant advances have been achieved over the last few years, with two JBTS loci (JBTS1, JBTS2) and two genes (JBTS3/AHI, NPHP1) characterised so far. While NPHPI is mostly responsible for isolated juvenile NPH, the identification of NPHPl deletions in patients with COGAN syndrome, ${ }^{18}{ }^{19}$ with cerebellar vermis hypoplasia, ${ }^{2021}$ and more recently with the MTS $^{22}$ broadens the NPHPl related clinical spectrum of diseases to include cerebellar involvement.

In this study we report a large cohort of patients with JSRD and confirm that NPHPI deletions can indeed be responsible for JSRD. We found one patient with the NPHPl deletion, who presented a full blown phenotype with early signs of kidney involvement and a typical pigmentary retinopathy.

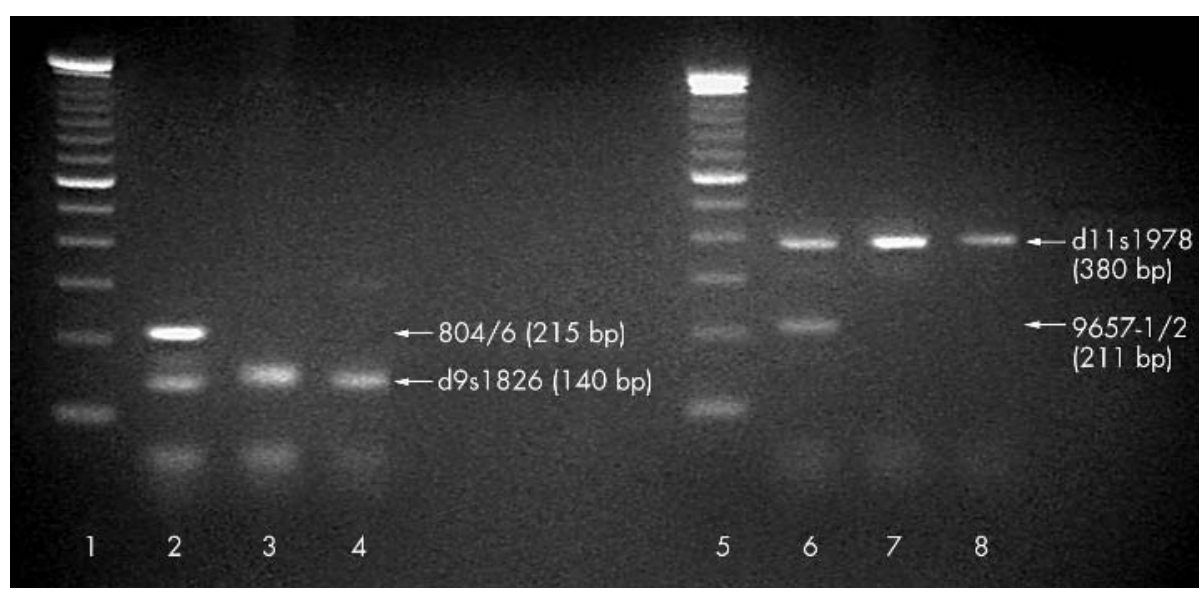

Figure 1 Analysis of NPHP1 deletion. Lanes 1 and 5: $100 \mathrm{bp}$ DNA size standard; lanes 2 and 6: multiplex A and $B$ for the negative control (healthy subject); lanes 3 and 7: multiplex $A$ and $B$ for patient $E C$; lanes 4 and 8 : multiplex $A$ and $B$ for the positive control (patient with juvenile NPH and with previously confirmed NPHP1 deletion). In patient $\mathrm{EC}$, the analysis showed a homozygous deletion of both markers $804 / 6$ and 9657 T-1/2, while the two control markers amplified normally. 

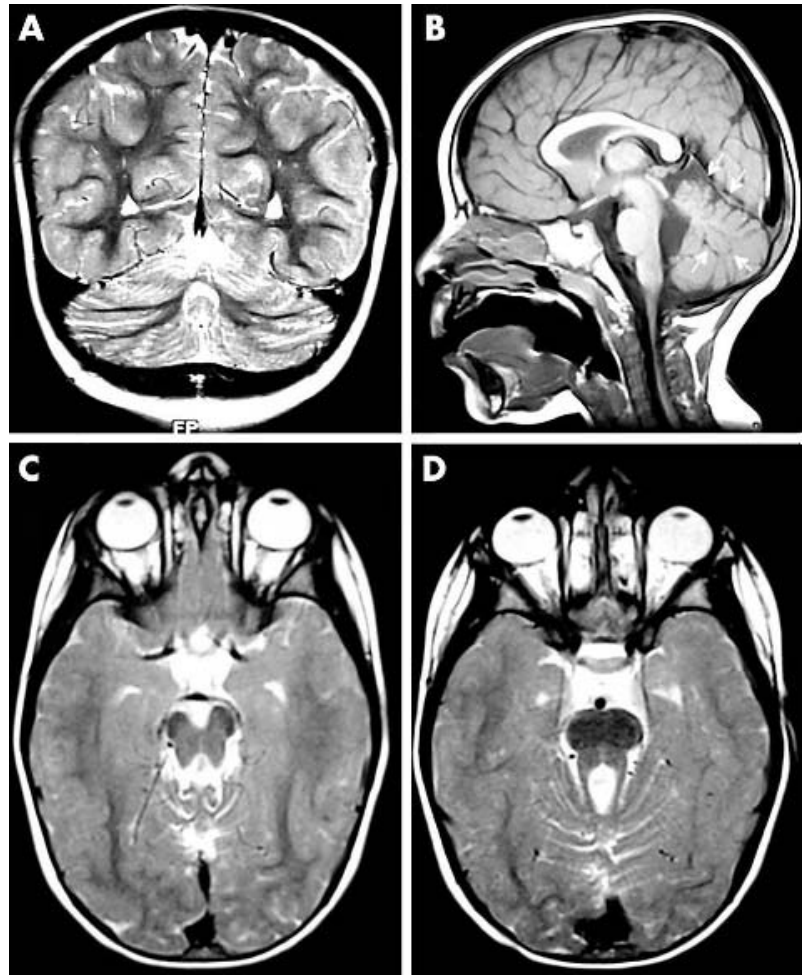

Figure 2 MRI of patient EC. Coronal T2 weighted sections at the level of the cerebellum showing hypoplasia of the inferior vermis (A). Sagittal T1 images passing through the midline showing abnormal fourth ventricle with inferior vermis hypoplasia (B, arrows circle the hypoplastic vermis) Axial T2 weighted images passing though the mesencephalon pontine junction showing the MTS and elongated superior cerebellar peduncles (C and D).

Conversely, none of the three patients described by Parisi et al had retinal involvement. ${ }^{22}$

Despite this phenotypic diversity, the appearance of the MTS in the four JSRD patients with NPHPl deletion is remarkably similar, showing moderate cerebellar vermis hypoplasia and elongated but not thickened superior cerebellar peduncles (fig 2A-D; see also fig 1 in Parisi et al). This peculiar presentation of the MTS might be specifically associated with NPHPl deletions, but this requires confirmation in additional cases.

When combining our results with the data from Parisi and colleagues, it appears that NPHPI deletions are found only in a minority $(4-7 \%)$ of patients with JS plus renal and/or retinal involvement. This low frequency is confirmed by a previous study, which failed to detect NPHP1 deletions in 13 patients with JS type B. ${ }^{24}$

It should be noticed that juvenile NPH can have a prolonged sub-clinical course until renal insufficiency develops and progress to end-stage renal failure, usually in the second decade of life. Therefore, recognition of renal involvement in patients with JS can be difficult in young children, such as in our patient, who only presented with mild polyuria. Since impaired urinary concentration ability is often the first sign of NPH, early diagnosis may require a urinary concentration test after Desmopressin stimulation or with a water restriction test, together with renal ultrasound. Although no specific treatment is available, early diagnosis of $\mathrm{NPH}$ is crucial to anticipate the development of renal symptoms. This allows prompt symptomatic treatments to be set up which may delay the progression towards end-stage renal failure and prevent the development of complications, such as growth failure or renal bone disease.
In conclusion, we have confirmed that NPHPl deletions could be a minor cause of JSRDs with renal and/or retinal involvement. Further studies are needed to clarify the prevalence and phenotypes of NPHPI associated JSRD and to confirm the peculiar appearance of the MTS in this subgroup of patients.

\section{ACKNOWLEDGEMENTS}

We are grateful to Drs GM Ghiggeri and G Caridi, who kindly donated DNA from an NPHPI deleted patient.

\section{Authors' affiliations}

M Castori, E M Valente, S Salvi, T Galluccio, B Dallapiccola, IRCCS

C.S.S., Mendel Institute, Rome, Italy

M A Donati, E Procopio, Department of Paediatrics, University of Florence, Meyer Children's Hospital, Florence, Italy

E Fazzi, Department of Child Neurology and Psychiatry, IRCCS

"C. Mondino Foundation", University of Pavia, Pavia, Italy

F Emma, Division of Nephrology and Dialysis, Department of Laboratory Medicine, Bambino Gesu' Hospital, Rome, Italy

E Bertini, Molecular Medicine Unit, Department of Laboratory Medicine, Bambino Gesu' Hospital, Rome, Italy

This work was supported by grants from M.U.R.S.T., the Italian Ministry of Health (Ricerca Corrente, Ricerca Finalizzata), and the NIH (grant R01 NS048453-01).

\section{Conflict of interest: none declared.}

*Other participants of the Italian MTS Study Group are: Roberta Battini, Pisa; Stefania Bova, Pavia; Loredana Boccone, Cagliari; Francesco Brancati, Rome; Silvana Briuglia, Messina; Roberta Cilio, Rome; Marilù Di Sabato, Rome; Rita Fischetto, Bari; Mattia Gentile, Bari; Vincenzo Leuzzi, Rome; Eugenio Mercuri, Rome; Pasquale Parisi, Rome; Martino Ruggieri, Catania; Damiano Carmelo Salpietro, Messina; Sabrina Signorini, Pavia; and Gaetano Tortorella, Messina.

Ethics approval: this study was approved by the IRCCS CSS (Mendel Institute) Ethical Committee, San Giovanni Rotondo, Italy (full IRB review certification on November 4th, 2003).

Correspondence to: Dr Enrico Bertini, Molecular Medicine Unit, Department of Laboratory Medicine, Bambino Gesu' Hospital IRCCS, Piazza S. Onofrio, 4, 00165 Rome, Italy; bertini@opbg.net

Revised version received 25 October 2004 Accepted for publication 31 October 2004

\section{REFERENCES}

1 Maria BL, Hoang KB, Tusa RJ, Mancuso AA, Hamed LM, Quisling RG, Hove MT, Fennell EB, Booth-Jones M, Ringdahl DM, Yachnis AT, Creel G, Frerking B. "Joubert syndrome" revisited: key ocular motor signs with magnetic resonance imaging correlation. J Child Neurol 1997;12:423-30.

2 Saraiva JM, Baraitser M. Joubert syndrome: a review. Am J Med Genet 1992;43:726-31.

3 Chance PF, Cavalier L, Satran D, Pellegrino JE, Koenig M, Dobyns WB. Clinical nosologic and genetic aspects of Joubert and related syndromes. J Child Neurol 1999; 14:660-6.

4 Satran D, Pierpont ME, Dobyns WB. Cerebello-oculo-renal syndromes including Arima, Senior-löken and $\mathrm{COACH}$ syndromes: more than just variants of Joubert syndrome. Am J Med Genet 1999;86:459-69.

5 Gleeson JG, Keeler LC, Parisi MA, Marsh SE, Chance PF, Glass IA, Graham Jr JM, Maria BL, Barkovich AJ, Dobyns WB. Molar tooth sign of the midbrain-hindbrain junction: occurrence in multiple distinct syndromes. Am J Med Genet 2004;125A:125-34.

6 Saar K, Al-Gazali L, Sztriha L, Rueschendorf F, Nur-E-Kamal M, Reis A, Bayoumi R. Homozygosity mapping in families with Joubert syndrome identifies a locus on chromosome 9q34.3 and evidence for genetic heterogeneity. Am J Hum Genet 1999:65:1666-71.

7 Keeler LC, Marsh SE, Leeflang EP, Woods CG, Sztriha L, Al-Gazali L, Gururaj A, Gleeson JG. Linkage analysis in families with Joubert syndrome plus oculo-renal involvement identifies the COR2 locus on chromosome 11 p12-q13.3. Am J Hum Genet 2003;73:656-62.

8 Valente EM, Salpietro DC, Brancati F, Bertini E, Galluccio T, Tortorella G, Briuglia S, Dallapiccola B. Description, nomenclature, and mapping of a novel cerebello-renal syndrome with the molar tooth malformation. Am J Hum Genet 2003:73:663-70.

9 Lagier-Tourenne C, Boltshauser E, Breivik N, Gribaa M, Betard C, Barbot C, Koenig M. Homozygosity mapping of a third Joubert syndrome locus to $6 q 23$. J Med Genet 2004;41:273-7. 
10 Ferland RJ, Eyaid W, Collura RV, Tully LD, Hill RS, Al-Nouri D, AlRumayyan A, Topcu M, Gascon G, Bodell A, Shugart YY, Ruvolo M, Walsh CA. Abnormal cerebellar development and axonal decussation due to mutations in AHI1 in Joubert syndrome. Nat Genet 2004;36:1008-13.

11 Hildebrandt F, Otto E, Rensing C, Nothwang HG, Vollmer M, Adolphs J Hanusch $\mathrm{H}$, Brandis $M$. A novel gene encoding an $\mathrm{SH} 3$ domain protein is mutated in nephronophthisis type 1. Nat Genet 1997;17:149-53.

12 Otto EA, Schermer B, Obara T, O'Toole JF, Hiller KS, Mueller AM, Ruf RG Hoefele J, Beekmann F, Landau D, Foreman JW, Goodship JA, Strachan T, Kispert A, Wolf MT, Gagnadoux MF, Nivet H, Antignac C, Walz G, Drummond IA, Benzing T, Hildebrandt F. Mutations in INVS encoding Inversin cause nephronophthisis type 2, linking renal cystic disease to the function of primary cilia and left-right axis determination. Nat Genet 2003;34:413-20.

13 Olbrich H, Fliegauf $M$, Hoefele J, Kispert A, Otto E, Volz A, Wolf MT, Sasmaz G, Trauer U, Reinhardt R, Sudbrak R, Antignac C, Gretz N, Walz G, Schermer B, Benzing T, Hildebrandt F, Omran H. Mutations in a novel gene NPHP3, cause adolescent nephronophthisis, tapeto-retinal degeneration and hepatic fibrosis. Nat Genet 2003;34:455-9.

14 Mollet G, Salomon R, Gribouval O, Silbermann F, Bacq D, Landthaler G, Milford D, Nayir A, Rizzoni G, Antignac C, Saunier S. The gene mutated in juvenile nephronophthisis type 4 encodes a novel protein that interacts with nephrocystin. Nat Genet 2002;32:300-5.

15 Caridi G, Dagnino M, Gusmano R, Ginevri F, Murer L, Ghio L, Piaggio G, Ciardi MR, Perfumo F, Ghiggeri GM. Clinical and molecular heterogeneity of juvenile nephronophthisis in Italy: insights from molecular screening. Am J Kidney Dis 2000;35:44-51

16 Hildebrandt F, Rensing C, Betz R, Sommer U, Birnbaum S, Imm A, Omran H, Leipoldt $M$, Otto $E$, Arbeitsgemeinschaft fur Paediatrische Nephrologie (APN) Study Group. Establishing an algorithm for molecular genetic diagnostics in 127 families with juvenile nephronophthisis. Kidney Int 2001;59:434-45.
17 Caridi G, Murer L, Bellantuono R, Sorino P, Caringella DA, Gusmano R Ghiggeri GM. Renal-retinal syndromes: association of retinal anomalies and recessive nephronophthisis in patients with homozygous deletion of the NPHI locus. Am J Kidney Dis 1998;32:1059-62.

18 Saunier S, Morin G, Calado J, Bennessy F, Silbermann F, Antignac C. Large deletions of the NPHI region in COGAN syndrome (CS) associated with familial juvenile nephronophthisis (NPH) [abstract]. Am J Hum Genet 1997;61(suppl):A346.

19 Betz R, Rensing C, Otto E, Mincheva A, Zehnder D, Lichter P, Hildebrandt F. Children with ocular motor apraxia type Cogan carry deletions in the gene (NPHP1) for juvenile nephronophthisis. J Pediatr 2000;136:828-31.

20 Takano K, Nakamoto T, Okajima M, Sudo A, Uetake K, Saitoh S. Cerebellar and brainstem involvement in familial juvenile nephronophthisis type I. Pediatr Neurol 2003:28:142-4.

21 Graber D, Antignac C, Deschenes G, Coulin A, Hermouet Y, Pedespan JM Fontan D, Ponsot $G$. Hypoplasies vermiennes avec atteintes extracérébrales (rétine, rein, foie) : des syndromes difficiles à classer. Arch Pediatr 2001:8:186-90.

22 Parisi MA, Bennett CL, Eckert ML, Dobyns WB, Gleeson JG, Shaw DW, McDonald R, Eddy A, Chance PF, Glass IA. The NPHPI gene deletion associated with juvenile nephronophthisis is present in a subset of individuals with Joubert Syndrome. Am J Hum Genet 2004;75:82-91.

23 Heninger E, Otto E, Imm A, Caridi G, Hildebrandt F. Improved strategy for molecular genetic diagnostics in juvenile nephronophthisis. Am J Kidney Dis 2001;37:1131-9

24 Hildebrandt F, Nothwang HG, Vossmerbaumer U, Springer C, Strahm B, Hoppe B, Keuth B, Fuchshuber A, Querfeld U, Neuhaus TJ, Brandis M and members of the APN Study Group. Lack of large, homozygous deletions of the nephronophthisis 1 region in Joubert syndrome type B. Pediatr Nephrol 1998; 12:16-9. 